\title{
Mediating effects of sea urchins on interactions among corals, algae and herbivorous fish in the Moorea lagoon, French Polynesia
}

\author{
B. D. Mapstone ${ }^{1, *}$, N. L. Andrew ${ }^{2}$, Y. Chancerelle ${ }^{3}$, B. Salvat ${ }^{3,4}$ \\ ${ }^{1}$ Antarctic Climate \& Ecosystem CRC, University of Tasmania, Private Bag 80, Hobart, Tasmania 7001, Australia \\ ${ }^{2}$ WorldFish Center, PO Box 500, GPO, 10670 Penang, Malaysia \\ ${ }^{3}$ Centre de Recherches Insulaires et Observatoire de l'Environnement, EPHE, BP 1013, Moorea, French Polynesia \\ ${ }^{4}$ Laboratoire de Biologie Marine, URA CNRS 8046, EPHE, Université de Perpignan, 66860 Perpignan Cedex, France
}

\begin{abstract}
The relative importance of grazing by sea urchins in influencing the composition and structure of coral reef habitats has only occasionally been explored experimentally, and never on the coral reefs of Oceania, where both herbivorous fishes and sea urchins are often common. In this paper we report the results of an experiment in French Polynesia, in which densities of an abundant sea urchin, Echinometra mathaei, were manipulated within the territories of an abundant omnivorous, 'gardening' pomacentrid fish (Stegastes lividus) in thickets of Acropora pulchra. Increasing the sea urchin density resulted in reductions in the standing crop of algae and over-grazing of the dead coral substratum on which the algae grew. After $2 \mathrm{yr}$ of this treatment, the coral thickets began to collapse. Reducing sea urchin densities to very low levels also resulted in collapse of the coral thickets and reduced densities of the fish, although algal biomass was apparently unaffected. We posit that the fish-coral-sea urchin-algal assemblage is relatively robust to wide fluctuations in sea urchin densities, but when sea urchin densities are driven to extremes the coral-algal habitat becomes destabilised and the entire system collapses, possibly as a result of different bioerosion processes in play at high and low sea urchin densities.
\end{abstract}

KEY WORDS: Herbivory · Bioerosion · Sea urchins · Coral · Algae · Urchin-coral interactions · Algal-coral interactions

\section{INTRODUCTION}

Sea urchins can significantly affect the ecological structure of coral reefs through bioerosion of substrata (Bak 1990, 1994, Conand et al. 1998) and by influencing competition for space between corals and algae (e.g. Ogden \& Lobel 1978, Hay 1981, 1984, 1991, Williams 1981, Lewis \& Wainwright 1985, Carpenter 1986, 1990, Foster 1987a,b, Morrison 1988, Coyer et al. 1993). Focus on coral-algae competition is increasing as concern grows about long-term alteration of ecological states of coral reefs (see review by McCook et al. 2001), with algal-dominated or coral-dominated communities considered by some to be alternate, potentially stable ecological states (Done 1992, Hughes 1994, Miller 1998, McClanahan et al. 2002a,b). Herbi- vores, including sea urchins, have been invoked as important mediators of this coral-algae competition, with corals apparently dominating when algae are suppressed by abundant grazers (Morrison 1988, Coyer et al. 1993). Changes in abundance of herbivores have been associated with blooms in benthic algae and overgrowth and, ultimately, limitation of coral recruitment and survival (Hughes et al. 1987, McManus et al. 2000, Williams \& Polunin 2001). Similarly, when herbivorous fish are prevented from grazing by the territoriality of some pomacentrids, algae dominate the substratum in the protected territories (Potts 1977, Klump et al. 1987, Hata et al. 2004).

Bio-erosion by sea urchins, either through specific burrowing activities or through inadvertent scraping of substrata during feeding, has been found to interact 
with the herbivore-algae-coral dynamics, both influencing and responding to the dynamics of coral and algal occupation of space on coral reefs (Risk \& Sammarco 1982, Sammarco et al. 1987, Bak 1990, 1994, Eakin 1996, Conand et al. 1998, Carreiro-Silva \& McClanahan 2001, Stromberg \& Kvamemo 2005). Sea urchins, therefore, can play diverse roles in a complex of interactions influencing the structure of coral reef communities.

Fisheries for predators have also been invoked in the coral-algae dynamics because of the top-down effects of removing the predators of the herbivores that mediate the algal-coral interactions (Hughes et al. 1987, McManus et al. 2000). For example, in heavily fished areas of the Caribbean, Diadema setosum consumed much of the algal primary production in areas affected by fishing, and their removal, or loss to disease, caused significant increases in the standing crop of algae (Hughes et al. 1987, Lessios 1988). In unfished areas, herbivorous fish are thought to out-compete sea urchins and to play a more important ecological role (Hay 1981, Robertson 1991).

Although the diadematid sea urchins are perhaps the most studied ecologically, sea urchins in the genera Tripneustes, Lytechinus and Echinometra may also be abundant on coral reefs and in seagrass habitats. Recent reviews suggest that Tripneustes spp. have relatively little impact on community structure (Lawrence \& Agatsuma 2001), and the large impacts observed for Lytechinus spp. are restricted to seagrass and associated habitats (Watts et al. 2001). McClanahan and coworkers (Carreiro-Silva \& McClanahan 2001, see review by McClanahan \& Muthiga 2001) have demonstrated, however, that Echinometra mathaei is an important grazer on heavily fished reefs in Kenya. In both Kenya and the Caribbean, sea urchins may play important roles in both herbivory and bioerosion, but their impact is density-dependent and mediated by other processes such as predation and fishing.

By contrast, on the Great Barrier Reef sea urchins are generally at very low abundance and herbivorous fishes are considered the most important herbivores (Russ 1987, 2003). Sea urchins also are considered to be less important than herbivorous fishes in the eastern Pacific and in Oceania (Ogden 1987, Sammarco 1987), even though relatively high densities of sea urchins have been recorded in some areas, such as some islands in French Polynesia. For example, sea urchins are very abundant on the lagoonal and fringing reefs around Moorea (Bak 1990, Conand et al. 1998), where a diversity of herbivorous fishes is also found, including scarids, acanthurids and the territorial damselfishes Stegastes nigricans and S. lividus (Galzin 1987a,b). The sea urchins at Moorea are principally Echinometra mathaei, Echinothrix diadema and
Diadema savignyi, and these sea urchins have been implicated in both herbivory and bioerosion (Bak 1990, Carreiro-Silva \& McClanahan 2001).

Relatively low densities of sea urchins are found in the Stegastes nigricans and S. lividus territories on consolidated reefs in the Moorea lagoon, where the sea urchins are found in holes or crevices within small patches of bare substratum surrounded by the algal turf that characterises the damselfish territories (B. D. Mapstone unpubl. data). Sea urchins displaced from the holes or crevices during daylight are evicted from the turfs by the damselfish, indicating active interference competition between the fish and sea urchins. Sea urchins are more abundant in damselfish territories in thickets of Acropora spp., however, particularly near the bases of the corals, below a band of dense epiphytic filamentous algae characteristic of the pomacentrids' territories. Roaming schools of grazing scarids and acanthurids are prevented from grazing within the thickets by attacks by the pomacentrids (B. D. Mapstone unpubl. data). Predatory fishes such as haemulids and labrids also are driven off by the pomacentrids.

Anecdotes indicated that the Acropora spp. thickets in the Moorea lagoon have changed considerably in location and extent over recent decades. The reasons for these changes are unknown, but one hypothesis is that over-grazing by sea urchins may have weakened the bases of the Acropora spp. and, ultimately, led to the collapse of the thickets. Such a process would indicate an important structuring role for the sea urchin grazers besides the suppression of algal growth.

In this paper we report the results of a manipulative experiment to explore the hypothesis that sea urchins may have direct (bio-erosion) as well as indirect (via grazing algae) density-dependent effects on the algalcoral-damselfish assemblage in coral thickets in the Moorea lagoon. We tested the null hypothesis that sea urchin density had no significant effect by directly manipulating the densities of the sea urchin Echinometra mathaei within territories of the pomacentrids Stegastes nigricans and S. lividus in lagoonal thickets of Acropora pulchra and monitoring the subsequent status of the algal turf, living coral, fish and thicket structure over 2 yr. This work is one of the few attempts to test through manipulative experiments the models derived from observation of patterns or natural disturbances in one or more of these components of coral reef systems.

\section{MATERIALS AND METHODS}

Study site. The experiment was done in an extensive area of Acropora pulchra in the lee of Motu Fare off the north west tip of Moorea Island $\left(17^{\circ} 29^{\prime} \mathrm{S}\right.$, 
$149^{\circ} 55^{\prime}$ W). Stegastes lividus was abundant, and individuals vigorously defended territories throughout the thickets. S. nigricans was less abundant and inhabited the margins of the thickets. The coral extended up to $50 \mathrm{~cm}$ above a semi-consolidated substratum of sand and rubble in approximately 1 to $2 \mathrm{~m}$ of water. Approximately the top third of the Acropora pulchra branches was living coral. A thick filamentous algal turf grew on the dead branches of the coral below the living extremities within the pomacentrid territories. The sea urchin Echinometra mathaei was abundant throughout the bases of the thickets. Much of the algae was removed where the sea urchins were at apparently high density, exposing the underlying dead basal branches of the coral. Other species of sea urchins (Echinothrix spp. and Diadema spp.) were rare in the A. pulchra thickets.

Aerial photography - recent history of the Acropora pulchra thickets. Black and white aerial photographs of the motu taken in 1977, 1981, 1984, 1986 and 1994 were sourced from Service de l'Urbanisme (town planning service) in French Polynesia. Distinct differences between the area now occupied by A. pulchra thickets (dark images) and the surrounding sand (light) were apparent in all these photographs. Although the extent of the dark areas in the photographs varied among years, the overall location remained the same; we interpreted these as coral thickets (see Fig. 1) and the white and light grey areas as sand and consolidated rubble. This distinction was consistent with our direct observations of the area from 1996 to 1998, with those of one of us (B. D. Mapstone) from 1986 to 1987 and detailed knowledge of the reefs around the motu for many years (B. Salvat). The photographs were scanned at $600 \mathrm{dpi}$ and image-rectified (that is, scaled against each other). Changes in area were calculated from the scanned images relative to the area in the last photograph (1994). Because these images could not be geo-rectified, the changes in relative area among years should be treated as indicative only of general increases or decreases rather than as a precise assessment of extent.

Experimental design. We manipulated the density of Echinometra mathaei in thickets of Acropora pulchra divided into 16 plots separated by at least $2 \mathrm{~m}$ of bare substratum. Coral was removed from the areas between plots to ensure they were isolated from each other by sand. Four plots were randomly allocated to each of 4 sea urchin density treatments: un-manipulated controls and zero, half and double ambient densities of E. mathaei measured prior to the manipulations. The latter 3 treatments were established by moving E. mathaei among the 12 plots involved. No sea urchins were observed to move across the sand barriers between plots during daylight, though 3 indi- viduals were observed beyond the thickets during 2 night-time inspections.

The experiment began in May to June 1996 and ended in July 1998. The complete sea urchin removal treatments were maintained at approximately monthly intervals for the duration of the experiment. On average, 33 sea urchins ( $\mathrm{SE}=3.8, \mathrm{n}=80$ ) were removed from each plot on each occasion, presumably reflecting occasional nocturnal movement of sea urchins among plots and emergence of cryptic sea urchins that were missed in the original removals. Every second month, 100 sea urchins were added to the double density treatment to offset expected low levels of nocturnal emigration and mortality and to maintain these plots with relatively elevated densities. There was no additional manipulation of either the control or 0.5 density treatments. These actions maintained the relative densities in the experimental treatments over the $2 \mathrm{yr}$, despite changes in the absolute abundances of sea urchins in the plots (see 'Results'). The experiment was sampled in June 1996 (immediately after set-up), June 1997 and July 1998.

Data collection. Sea urchins: Densities of visible Echinometra matheai were estimated in ten $1 \mathrm{~m}^{2}$ quadrats per plot on each annual sampling occasion. The coral was not disturbed during the counts, so some cryptic individuals would have been missed. In May 1996 only, 10 quadrats were sampled destructively in an area of Acropora pulchra adjacent to the experimental plots to estimate the proportions of sea urchins that were not visible during the quadrat sampling. This sampling was done by counting and removing the visible sea urchins from the $1 \mathrm{~m}^{2}$ quadrats and then carefully removing and searching the A. pulchra for cryptic individuals, which also were removed and measured to the nearest millimeter along the long axis of the test.

Live coral, dead coral and algae: The volumes of live coral, dead coral and algae were estimated as a surrogate for biomass. All the coral and attached algae were removed from randomly selected $0.25 \mathrm{~m}^{2}$ quadrats in each plot and the volumes were estimated in the laboratory by displacement, as follows. First, the live sections of coral branches were separated from the dead sections and their volumes were estimated by emersion in water in a volumetric cylinder. Second, the combined volume of dead coral with attached algae was similarly estimated. Third, the dead coral branches were bleached overnight and cleaned to remove the algal mat. Finally, the volume of the bleached and cleaned dead branches was estimated and the separate volume of algae was calculated by subtraction of these volumes from those of the dead coral + algae measured in the second step. Two replicate quadrats were sampled per plot in both 1997 and 
1998 but only 1 quadrat was sampled per plot at the start of the experiment, to minimize impacts of the destructive sampling on treatments. The density of live coral apices in thickets was also estimated from in situ counts of live apices within ten $0.25 \mathrm{~m}^{2}$ quadrats in each plot each year.

Fish: The density of Stegastes lividus in each plot was estimated each year in single $5 \times 2 \mathrm{~m}$ belt transects laid across the centre of each plot. Fish were counted in 3 size categories: adults, sub-adults and recent recruits, but counts were pooled over all size categories before analysis because sub-adults and recruits were rare. Because the fish moved rapidly across transect boundaries and darted in and out of the coral thickets, each transect was surveyed 3 times over $10 \mathrm{~min}$ and the counts averaged to provide estimates of densities. Densities of $S$. nigricans were estimated within a $1 \mathrm{~m}$ wide belt around the perimeter of each plot because this species tended to inhabit only the margins rather than the centres of the thickets. Counts for this species also were pooled over all size categories before analysis because relatively few recruits or sub-adult fish were seen.

Analyses. Our effective experimental units (Hurlbert 1984) were plots, each of which was sampled on each sampling occasion. Quadrats sampled within plots on each occasion were sub-samples from which we derived estimates of the mean status of each plot at each sampling time but which also allowed for tests of homogeneity among plots within treatments and at each sampling time. Hence, data from the experiment were analysed by repeated-measures ANOVAs in which the between-subject effects were Treatment (fixed) and Plot (random replicates) and the withinsubject effect was Time (sampling year, fixed). We used Pillai's trace to test within-subject effects.

Tests for treatment effects on contrasts between successive times were done as part of the repeated-measures ANOVAs and differences among treatments at each time were tested by separate single-factor ANOVAs followed by Tukey's HSD (honestly significant difference) tests when significant Treatment effects were indicated. The analyses were done in SAS using Type III sums of squares. Sphericity of the repeated-measures data was tested by Mauchly's criterion and homoscedasticity of error variances was tested by O'Brien's modification of Levine's test (O'Brien 1979).

Counts of Echinometra matheai and live coral tips were analysed as mean densities per plot after averaging over quadrats within plots. The total volumes of habitat (algae + live coral + dead coral) removed from quadrats were averaged within plots and compared over time to assess treatment-specific and overall changes in the total amount of habitat in the plots. Volumes of algal biomass, dead coral and live coral were transformed to proportions of the total volume in each quadrat to standardise the metrics for changes in the total amount of habitat over time. These proportions were then averaged among quadrats within plots prior to analysis. In 1 case only (proportion of dead coral) were the assumptions of sphericity and homoscedasticity violated, because of an outlying value. Analyses of this variable with and without the outlier were consistent, so we present the results of analyses with the outlier included. We used $\mathrm{p} \leq 0.05$ as the criterion for significance in all tests.

\section{RESULTS}

\section{Aerial photographs}

The series of aerial photographs showed that the (presumed) thickets of Acropora pulchra at the study site had varied in area and shape over the $17 \mathrm{yr}$ period between the first and last photographs (Fig. 1). There was a monotonic decline in the estimated area of the thickets, with the estimated area of thicket in 1994 approximately half that of 1977. Most of this change seemed to arise from shrinking at the margins of the thicket, with the central areas appearing reasonably coherent in all photographs. From 1996 to 1998, we observed several semi-consolidated banks adjacent to the study site that were comprised of $A$. pulchra rubble and live remnants, suggesting there had been thickets there before. The rubble on these banks had been grazed clean of macroalgae and newly recruited corals were common.

\section{Initial conditions}

The experimental plots ranged in area from 17 to $63 \mathrm{~m}^{2}$, with the variation in areas largely due to the irregular natural boundaries of the thickets within which plots were demarcated. We avoided standardising plot area to the lowest common denominator because of the impact that the required removal of coral would have had on the gross extent of the thickets. The average plot sizes in 1996 were 37, 36, 35 and $21 \mathrm{~m}^{2}$ for the control, double-density, half-density and removal treatments, respectively, and these mean sizes were not significantly different (Table 1). Treatments and replicate plots were homogeneous immediately prior to manipulations with respect to most measured habitat variables (Table 1). The average densities of Echinometra mathaei, however, were significantly greater in plots destined for the 'double-density' treatment than in other plots prior to manipulation (Table 1, Tukey's HSD tests, Fig. 2), an artefact of the random allocation of treatments to plots. Given that all other 


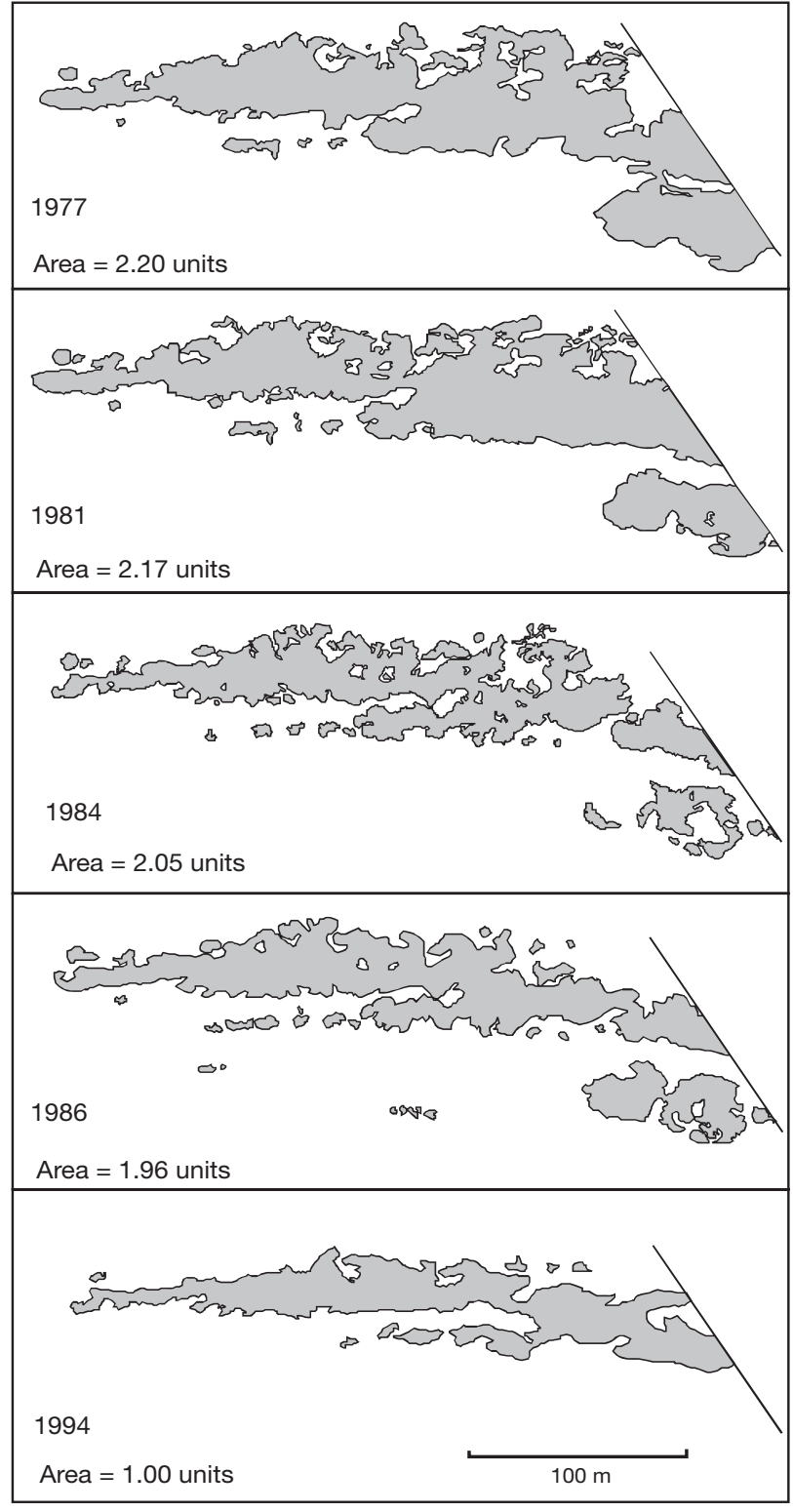

Fig. 1. Acropora pulchra. Maps of thickets at Moorea, French Polynesia taken from aerial photographs between 1977 and 1994. The photographs were image-rectified against consistent landmarks and the areas were standardised against the area observed in 1994, such that area in 1994 was one unit

variables were similar among plots, however, we inferred that this difference in sea urchin densities was unlikely to have corresponded with significant preexisting differences in habitat structure.

The size frequency of the visible population of Echinometra mathaei at the start of the experiment was unimodal, with a mean size of $32.2 \mathrm{~mm}$ test length $(\mathrm{SD}=7, \mathrm{n}=114)$. Destructive sampling indicated that an average of $11.7 \%(\mathrm{SD}=8.6, \mathrm{n}=10)$ of the population was cryptic and that these cryptic individuals
Table 1. Results of tests for homogeneity of variables among treatments and plots at the beginning of the experiment. Tests were by nested ANOVA with plots nested within treatments and samples (quadrats for coral tips and Echinometra matheai, random points for coral height) nested within plots. No test (-) for plot homogeneity was possible when only single samples were taken within plots (area, Stegastes nigricans, S. lividus, total and proportional volume metrics) Values in bold are significant at $\mathrm{p} \leq 0.05$ (Prop: proportion)

\begin{tabular}{|lcccccc|}
\hline \multirow{2}{*}{ Variable } & \multicolumn{3}{c}{ Treatments } & \multicolumn{3}{c|}{ Plots (Treatments) } \\
& $F$ & $\mathrm{df}$ & $\mathrm{p}$ & $F$ & $\mathrm{df}$ & $\mathrm{p}$ \\
\hline Area & 1.35 & 3,12 & 0.30 & - & - & - \\
Coral height & 0.75 & 3,12 & 0.54 & 0.77 & 12,144 & 0.68 \\
Coral tips & 0.49 & 3,12 & 0.70 & 1.06 & 12,137 & 0.39 \\
E. matheai & 3.85 & 3,12 & $\mathbf{0 . 0 4}$ & 4.46 & 12,133 & $<\mathbf{0 . 0 1}$ \\
S. lividus & 0.18 & 3,12 & 0.91 & - & - & - \\
S. nigricans & 1.52 & 3,12 & 0.26 & - & - & - \\
Total volume & 2.19 & 3,12 & 0.14 & - & - & - \\
Prop(algae) & 0.04 & 3,12 & 0.99 & - & - & - \\
Prop(dead) & 0.83 & 3,12 & 0.50 & - & - & - \\
Prop(live) & 0.53 & 3,12 & 0.67 & - & - & - \\
\hline
\end{tabular}

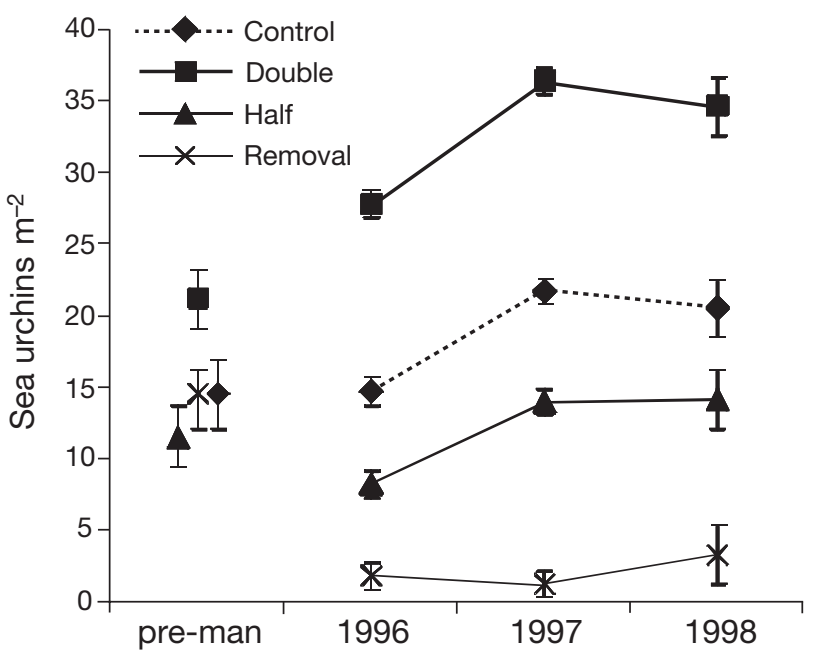

Fig. 2. Echinometra mathaei. Mean density of sea urchins (ind. per $\mathrm{m}^{2}, \pm \mathrm{SE}$ ) over the 4 quadrats in each treatment before experimental manipulations (pre-man: June 1996) and in June and July of each year following manipulations. Double, half, removal: double, half and zero ambient densities prior to manipulation

were generally smaller than the visible sea urchins, with unimodal size distribution and an average test length of $18.4 \mathrm{~mm}(\mathrm{SD}=8.7, \mathrm{n}=27)$.

\section{Effectiveness of manipulations}

The desired relative densities were established successfully at the beginning of the experiment and maintained successfully throughout the experiment, 
with mean densities significantly different among treatments in all years post-manipulation $\left(F_{3,12}=124.7,277.3\right.$ and 41.4 for 1996, 1997 and 1998, respectively, $\mathrm{p}<0.001$ in all cases; Fig. 2). Slight increases in density in the control plots between 1996 and 1997 were matched proportionally by increased densities in the double- and half-density treatments (Fig. 2). These increases were possibly a result of recruitment or an increase in the proportion of non-cryptic sea urchins, or both, but neither hypothesis could be tested because data on cryptic sea urchins were not collected after 1996.

\section{Responses to manipulations}

\section{Plot areas}

Thirteen of the 16 plots decreased in area by between 6 and $46 \%$ from 1996 to 1998. The remaining 3 plots increased in size by 6, 23 and $24 \%$. Mean plot areas in 1998 were 32, 29, 34 and $18 \mathrm{~m}^{2}$ for the control, double-density, half-density and removal treatments, respectively. These means did not differ significantly $\left(F_{3,12}=1.03, \mathrm{p}=0.414\right)$, nor did the mean changes in area between 1996 and 1998 differ significantly among treatments $\left(F_{3,12}=0.69, \mathrm{p}=0.57\right)$. Thus, there was no clear relationship between treatment and either area or change in area during the experiment.

\section{Thicket structure}

Several of the plots changed markedly in structure during the experiment. Most notable were substantial collapses of thickets in the plots from which all sea urchins were removed and collapses of small patches within plots with double ambient densities of Echinometra mathaei, the latter usually around areas with conspicuous local aggregations of E. mathaei. The algal mat in the double-density plots appeared to thin considerably over the $2 \mathrm{yr}$ and was almost totally absent from substantial areas of these plots. The dead branches of coral removed from the double-density plots were noticeably thinner than those from other plots in 1998.

Mean heights of the coral thickets changed through time in treatment-dependent ways (Time $\times$ Treatment interaction $\left.-F_{6,24}=2.67, \mathrm{p}=0.04\right)$ though only between 1997 and 1998 (1996 to $1997-F_{3,12}=0.67, \mathrm{p}$ $=0.59 ; 1997$ to $1998-F_{3,12}=5.05, p=0.02$; Fig. 3). Thicket height did not differ significantly among treatments in either $1996\left(F_{3,12}=1.79, \mathrm{p}=0.54\right)$ or 1997 $\left(F_{3,12}=0.97, \mathrm{p}=0.44\right.$; Fig. 3$)$, but by 1998 height of coral in all the manipulated plots had declined and was lower than in the controls $\left(F_{3,12}=5.93, \mathrm{p}=0.01\right.$,

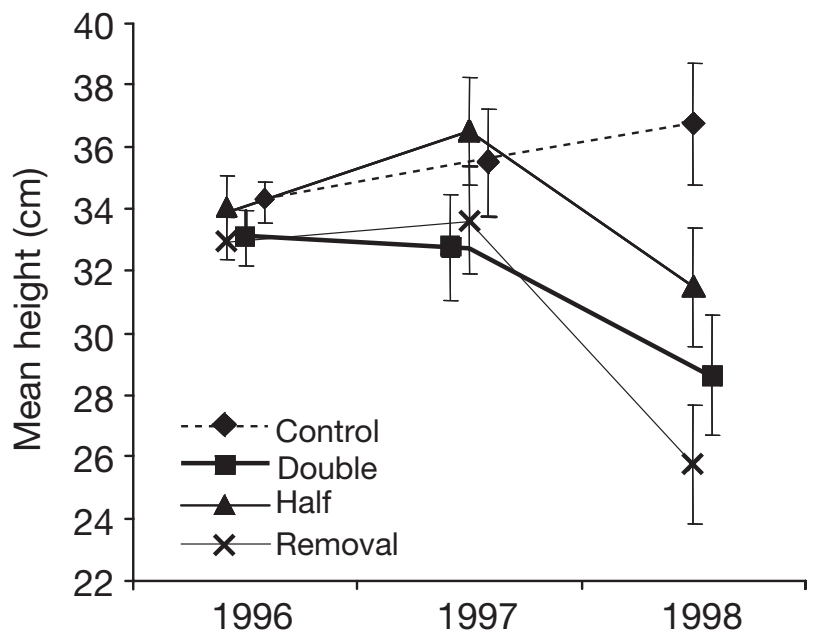

Fig. 3. Acropora pulchra. Mean height of the top of the thicket above the lagoon floor $(\mathrm{cm} \pm \mathrm{SE})$ per treatment at the time of manipulation (1996) and in 1997 and 1998. For explanation of treatments see Fig. 2

Tukey's HSD), with the removal and double-density treatments being the lowest (Fig. 3).

The density of living coral apices (per $0.25 \mathrm{~m}^{2}$ ) also changed during the experiment (Time effect $-F_{2,11}=$ 75.30, p < 0.001), increasing from 1996 (113) to 1997 (133) and decreasing thereafter (75 in 1998), but changes did not vary significantly with treatment (Time $\times$ Treatment interaction $-F_{6,24}=2.03, \mathrm{p}=0.10$ ).

\section{Biomass of thicket habitat}

The average total volumes of substrate (algae + dead coral + live coral) sampled from plots diverged among treatments during the experiment (Time $\times$ Treatment effect, $F_{6,24}=3.10, \mathrm{p}=0.02$ ), mainly because of a significant decline in volume of habitat in the double-density treatment (Fig. 4a). Volume of habitat in this treatment was significantly less than in all others in both 1997 $\left(F_{3,12}=4.46, \mathrm{p}=0.03\right.$, Tukey's HSD $)$ and $1998\left(F_{3,12}=\right.$ 9.97, $\mathrm{p}=0.001$, Tukey's HSD). There were no significant differences among other treatments in any year (Tukey's HSD).

\section{Composition of thicket habitat}

The proportion of habitat that was dead coral increased significantly in all treatments by similar amounts from 1996 to 1997 (Fig. 4b) (overall increase $-F_{1,12}=65.96, \mathrm{p}<0.001$; Treatment effect$\left.F_{3,12}=1.39, \mathrm{p}=0.293\right)$. Subsequently, the proportion of dead coral decreased similarly in the control, half-density and double-density treatments to levels close to 

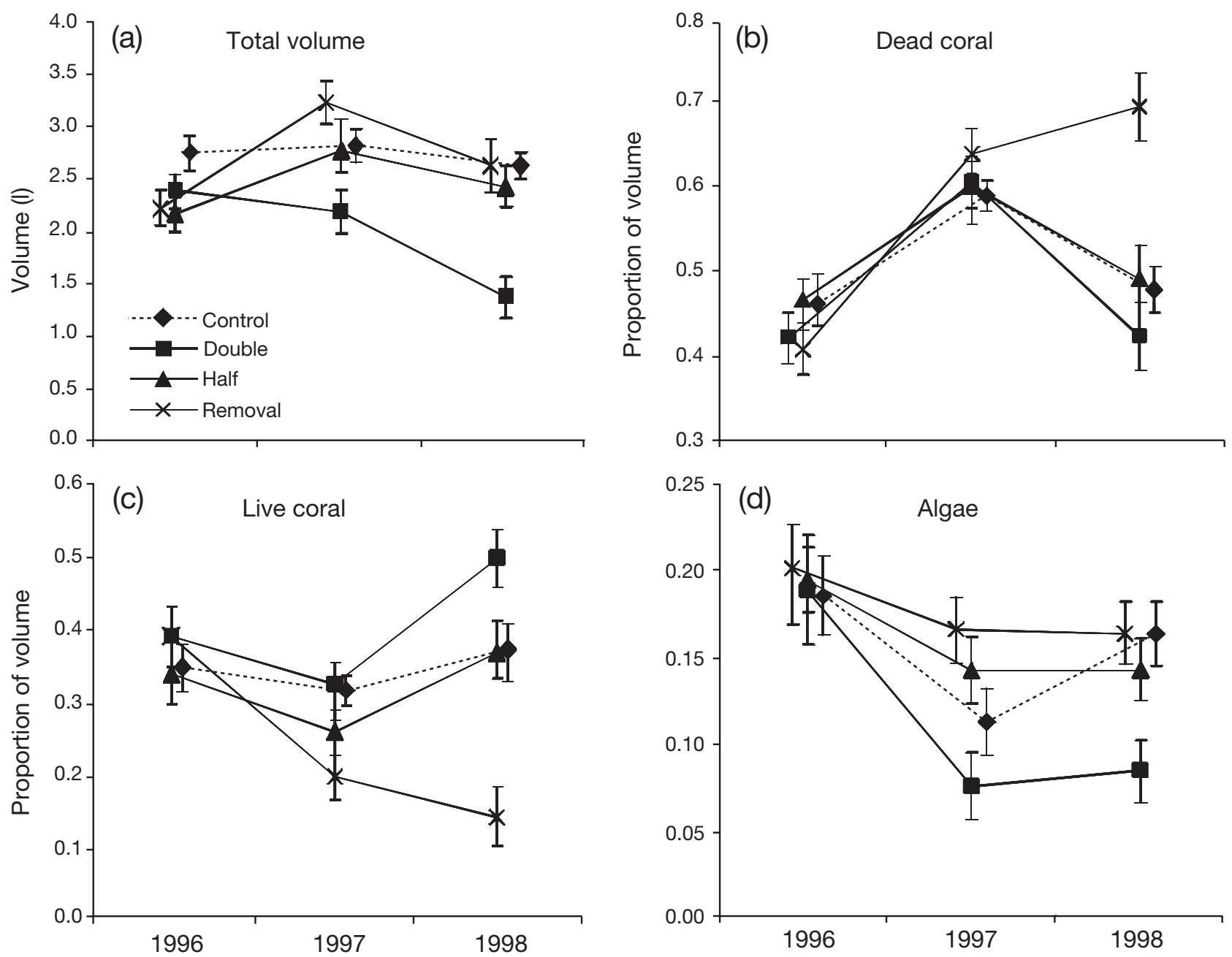

Fig. 4. Status of algae, live coral and dead coral at the time of manipulations in 1996 and responses over the 2 following years: (a) mean total volume of substratum (algae + dead coral + live coral, l per $0.25 \mathrm{~m}^{2}, \pm \mathrm{SE}$ ); (b) mean proportion of dead coral; (c) mean proportion of live coral; and (d) mean proportion of epiphytic turf algae. For explanation of treatments see Fig. 2

those from 1996 (Fig. 4b). Dead coral as a proportion of habitat in the removal treatment, however, continued to increase from 1997 to 1998 (treatment-specific changes $\left.-F_{3,12}=4.81, \mathrm{p}=0.020\right)$, such that it then differed significantly from the other 3 treatments $\left(F_{3,12}=\right.$ 7.33, $\mathrm{p}=0.005$, Tukey's HSD; Fig. 4b).

The proportional volume of live coral in the control and half-density treatments did not change significantly (temporal contrasts, $\mathrm{p}>0.05$ ) and remained similar to each other throughout the experiment (Fig. 4c). In contrast, live coral as a proportion of habitat in the double-density plots was stable from 1996 to 1997 but then increased in 1998 to a level $28 \%$ greater than in 1996 (Fig. 4c), whilst proportion of habitat comprised of live coral in the removal treatment declined significantly from 1996 to 1997 and remained low in 1998 (Fig. 4c). Consequently, in 1998, the proportion of habitat that was live coral was significantly greater in the double-density treatment than in all others and significantly less in the removal treatment than in all others $\left(F_{3,12}=11.78, \mathrm{p}<0.001\right.$, Tukey's HSD tests; Fig. $\left.4 \mathrm{c}\right)$.

The proportions of substratum comprised of algae changed significantly during the experiment (Time effect $-F_{2,11}=5.85, \mathrm{p}=0.02$ ) and differed among treatments averaged over all years $\left(F_{3,12}=3.92, \mathrm{p}=\right.$ $0.04)$, but the profiles over time were not treatment specific (Time $\times$ Treatment interaction $-F_{6,24}=1.22$, $\mathrm{p}=0.33$ ), despite apparent differentiation between the double-density and remaining treatments in 1997 and 1998 (Fig. 4d). In tests among treatments in each year, treatments were indistinguishable in $1997\left(F_{3,12}\right.$ $=0.06, \mathrm{p}=0.98)$ but differed significantly in both 1997 $\left(F_{3,12}=4.75, \mathrm{p}=0.02\right)$ and $1998\left(F_{3,12}=6.14, \mathrm{p}=0.01\right)$, with the double-density treatment having significantly lower proportions of algae than all other treatments (HSD tests). 


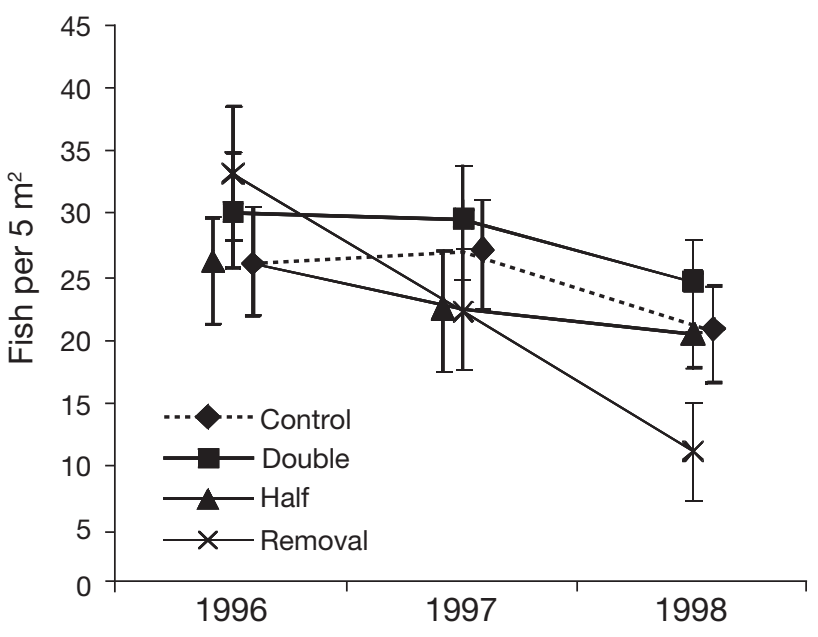

Fig. 5. Stegastes lividus. Mean density of fish (ind. per $5 \mathrm{~m}^{2}$, $\pm \mathrm{SE}$ ) over the 4 quadrats in each treatment at the time of experimental manipulations (June 1996) and in June and July of each year following manipulations. For explanation of treatments see Fig. 2

Fish

Densities of Stegastes lividus were similar in all treatments in 1996 (Table 1) and declined significantly overall during the experiment (Time effect $-F_{2,11}=$ 11.72, $\mathrm{p}=0.002$ ). Despite an apparently steeper and more consistent decline in abundances of $S$. lividus in the removal treatment plots than in other treatments (Fig. 5), the interaction between Time and Treatment was non-significant $\left(F_{6,24}=1.32, \mathrm{p}=0.29\right)$, meaning that treatment effects on $S$. lividus were not clear.

Densities of Stegastes nigricans around the margins of plots were consistently low $(0.38,0.39$ and 0.30 fish $\mathrm{m}^{-2}$ in 1996, 1997 and 1998, respectively) and did not vary significantly over time $\left(F_{2,11}=0.16, \mathrm{p}=0.85\right)$ or with treatment in any year ( $p>0.1$ in all years).

\section{DISCUSSION}

This study complements existing research on sea urchins and fishes at Moorea and contributes to understanding the complex mechanisms by which grazing by sea urchins may influence structure of coral reef ecosystems (Eakin 1996, Carreiro-Silva \& McClanahan 2001). We have shown that substantial changes in the population densities of a small sea urchin, Echinometra mathaei, had significant consequences for other components of a tropical reef habitat. These effects were not most manifest as the expected effect, on the epiphytic algae on which the sea urchins grazed, but rather involved impacts on the amounts of living and dead coral in the system and, ultimately, on the structural integrity of the thickets of Acropora pulchra. The indication of consistent, though not statistically significant, declines in densities of territorial pomacentrids in the collapsing thickets perhaps suggested that they, too, eventually might have been affected indirectly by the impacts or absence of the sea urchins on the coral thicket habitat. These results suggest that, in this habitat, interactions among sea urchins, fish and corals are likely to be complex and density dependent but not necessarily consistent with previous hypotheses.

The removal of sea urchins from plots ultimately resulted in a significant increase in dead coral substratum accompanied by a concurrent decrease in live coral biomass and reduction in thicket height. These changes were not accompanied by significant proportional changes in algal biomass, however, and so it is unlikely that the changes in coral were the result of overgrowth of living coral by algae under diminished grazing pressure (Hay 1981, 1984, Hughes et al. 1987 , Morrison 1988, Coyer et al. 1993, McCook et al. 2001).

Conversely, doubling ambient densities of sea urchins did result in relatively increased amounts of live coral and an approximately $65 \%$ reduction in the amount of algae in the thicket matrix. These changes are consistent with a hypothesis of reduced competition between coral and algae mediated by increased grazing pressure (Lewis \& Wainwright 1985, Coyer et al. 1993, Carreiro-Silva \& McClanahan 2001, McClanahan \& Muthiga 2001, McCook et al. 2001). The residence of the sea urchins below and live coral above the algal turf, however, suggests that increased grazing pressure may have had a negligible effect at the border between turf and living coral, where competition would be expected to be greatest (McCook et al. 2001).

The decline in thicket height in all manipulated treatments, particularly in the removal and doubledensity treatments, was consistent with our qualitative observations of substantial collapse of the thickets in the removal plots and patchy collapses in the doubledensity plots. We cannot be certain of the reasons for these collapses, but the responses discussed above suggest that different processes might have led to collapse in the different treatments. Specifically, the changes in response to increasing densities of sea urchins may have arisen because of 'cropping' of the algal turfs as sea urchins at higher population densities had to forage further over the turf. If so, this would implicate the well-recognised mechanism of grazermediated release of growing corals from competition (McCook et al. 2001) or physical stress (Coyer et al. 1993) from algae. Elevated grazing intensity in these treatments was also suggested by the observation of substantial thinning of the algal turfs and narrowing of the bases of coral branches, which would also contribute to thicket collapse. 
Reductions in sea urchin density, on the other hand, might not only have reduced or removed grazing at the lower margins of the turf, but might also have reduced direct grazing of the dead coral substratum below the turf. This latter release from grazing may have resulted in increased recruitment and survival of boring organisms (Risk \& Sammarco 1982, Sammarco et al. 1987, Stromberg \& Kvamemo 2005), which ultimately weakened the coral branches sufficiently to cause thicket collapse. Interactions among grazing, herbivory, algal cover and bio-erosion have previously been hypothesised from correlation data (Risk \& Sammarco 1982, Carreiro-Silva \& McClanahan 2001) and recently tested by manipulative experiments (Stromberg \& Kvamemo 2005). Whilst we did not measure either bioerosion or abundances of boring organisms directly, the responses we observed to removal of sea urchins from thickets are consistent with these previously proposed dynamics.

Under each of the above hypotheses, we would expect to see the complete collapse of the thickets if the densities of sea urchins remained at the highest or lowest levels of our experiment for a longer period of time (possibly after as short a time as 1 more year). If this occurred, we also would expect to see the disappearance of Stegastes lividus from those plots, probably through emigration, as their habitat disintegrated. The declining counts of $S$. lividus in the sea urchin removal plots may indicate the onset of such an exodus.

The absence of any consistent response to halving the ambient densities of Echinometra mathaei suggests that the dynamics of the coral-sea urchinalgae-fish system are probably robust to variations in sea urchin density over a fairly wide range, breaking down only when the sea urchin densities are taken to extremes. This result is consistent with our observations at the beginning of the experiment that the initially higher densities of sea urchins in some plots did not correspond with significant differences in other variables. Natural phenomena that might force sea urchin densities beyond the envelope within which this system appears relatively stable might include disease, recruitment pulses, or human interventions, such as pollution or fishing (Hughes et al. 1987, Lessios 1988, Hughes 1994, Miller 1998, McManus et al. 2000, Carreiro-Silva \& McClanahan 2001). It is unclear whether the densities of sea urchins in the habitats, and any consequential impacts are regulated in any way by density-dependent compensatory mechanisms affecting recruitment, growth, or mortality of the urchins.

The unusually high densities of sea urchins at Moorea may be the result of human impacts on the lagoonal system, especially through the removal of predators on sea urchins (Hughes et al. 1987, Lessios 1988, Hughes 1994, Miller 1998, McManus et al. 2000, Carreiro-Silva \& McClanahan 2001). In Acropora pulchra thickets, Echinometra mathaei might also benefit from the combination of the thicket structure which provides refuge against interference competition and displacement by Stegastes nigricans, the territoriality of which, in turn, incidentally provides sea urchins with a defence from predators. If this is the case, then the question arises as to the dynamics of the A. pulchra thickets prior to human impacts, when sea urchins would have been expected to be at substantially lower densities. Assuming that the territorial pomacentrids and associated algal turfs existed whether sea urchins were present or not, it might be expected from our results that the turnover of thickets would be substantially greater and more rapid in the absence of sea urchins than when they were at moderate densities.

The aerial photography we present indicates that the thickets are relatively dynamic over decadal scales, as does our observation of substantial banks comprised mainly of fragments of Acropora pulchra that may indicate the prior existence and collapse of entire thickets. We stress, however, that we are not able to infer that sea urchins directly caused the changes in thicket area observed in the aerial photography; we present these images only to illustrate the change that has occurred in the system over just 2 decades. This dynamism is likely to be exacerbated by periodic cyclones (e.g. in 1983 and 1992), but there is clear evidence that the changes in extent of thickets are not entirely due to such disturbances. The interactions between sea urchin densities and thicket structure may explain some of the changes in thickets during other periods. Moreover, the densities of sea urchins in the thickets may change significantly the vulnerability of thickets to physical damage from disturbances such as cyclones.

The role of sea urchins in structuring habitat is well established in some tropical systems, such as the Caribbean and Kenyan reefs (Hay 1981, 1984, Hughes et al. 1987, Lessios 1988, McClanahan \& Muthiga 2001). Our results suggest that under some circumstances at least, sea urchins may play similarly important roles in French Polynesia. We acknowledge that interactions may differ on consolidated back reefs where shelter is less abundant. Nevertheless, in the habitat we studied, sea urchins co-existed with territorial damselfishes across a wide range of densities, perhaps enhancing the persistence of a complex assemblage. Very high or very low densities of the sea urchins, however, may mediate the collapse of the coral thickets and the dissolution of the associated assemblages. 
Acknowledgements. This work was supported by the Australian Bilateral Science Program under the auspices of the Department of Industry, Trade and Regional Development and by the Universite de Perpignan and the French Government. We gratefully acknowledge the Centre de l'Environnement d'Opunohu on Moorea and are grateful to J. Algret for his assistance. We thank 4 anonymous reviewers for comments that significantly improved the manuscript.

\section{LITERATURE CITED}

Bak RPM (1990) Patterns of echinoid bioerosion in two Pacific coral reef lagoons. Mar Ecol Prog Ser 66:267-272

Bak RPM (1994) Sea urchin bioerosion on coral reefs: place in the carbonate budget and relevant variables. Coral Reefs 13:99-103

Carpenter RC (1986) Partitioning herbivory and its effects on coral reef algal communities. Ecol Monogr 56:345-363

Carpenter RC (1990) Mass mortality of Diadema antillarum. 2. Effects on population densities and grazing intensity of parrotfishes and surgeonfishes. Mar Biol 104:79-86

Carreiro-Silva M, McClanahan TR (2001) Echinoid bioerosion and herbivory on Kenyan coral reefs: role of protection from fishing. J Exp Mar Biol Ecol 262:133-153

Conand C, Heeb M, Peyrot-Clausade M, Fontaine MF (1998) Bioerosion by the sea urchin Echinometra on La Reunion reefs (Indian Ocean) and comparison with Taihura reefs (French Polynesia). In: Mooi R, Telford M (eds) Echinoderms. A.A. Balkema, Rotterdam, p 609-615

Coyer JA, Ambrose RF, Engle JM, Carroll JC (1993) Interactions between corals and algae on a temperate zone rocky reef: mediation by sea urchins. J Exp Mar Biol Ecol 167:21-37

Done TJ (1992) Phase shifts in coral reef communities and their ecological significance. Hydrobiologica 247: $121-132$

Eakin CM (1996) Where have all the carbonates gone? A model comparison of calcium carbonate budgets before and after the 1982-1983 El Niño at Uva Island in the eastern Pacific. Coral Reefs 15:109-119

Foster SA (1987a) The relative impacts of grazing by Caribbean coral reef fishes and Diadema: effects of habitat and surge. J Exp Mar Biol Ecol 105:1-20

Foster SA (1987b) Territoriality of the dusky damselfish: influence on algal biomass and on the relative impacts of grazing by fishes and Diadema. Oikos 50:153-160

Galzin R (1987a) Structure of fish communities of French Polynesian coral reefs. I. Spatial scales. Mar Ecol Prog Ser 41: 129-136

Galzin R (1987b) Structure of fish communities of French Polynesian coral reefs. II. Temporal scales. Mar Ecol Prog Ser 41:137-145

Hata H, Nishihira M, Kamura S (2004) Effects of habitat-conditioning by the damselfish Stegastes nigricans (Lacepede) on the community structure of benthic algae. J Exp Mar Biol Ecol 280:95-116

Hay ME (1981) Herbivory, algal distribution, and the maintenance of between-habitat diversity on a tropical fringing reef. Am Nat 118:520-540

Hay ME (1984) Patterns of fish and urchin grazing on Caribbean coral reefs: Are previous results typical? Ecology 65: 446-454

Hay ME (1991) Fish-seaweed interactions on coral reefs: effects of herbivorous fishes and adaptations of their prey. In: Sale PF (ed) The ecology of fishes on coral reefs. Academic Press, San Diego, CA, p 96-118
Hughes TP (1994) Catastrophes, phase-shifts and large-scale degradation of a Caribbean coral reef. Science 265:1-23

Hughes TP, Reed DC, Boyle M (1987) Herbivory on coral reefs: community structure following mass mortalities of sea urchins. J Exp Mar Biol Ecol 113:39-59

Hurlbert SH (1984) Pseudoreplication and the design of ecological field experiments. Ecol Monogr 54:187-211

Klump DW, McKinnon AD, Daniel P (1987) Damselfish territories: zones of high productivity on coral reefs. Mar Ecol Prog Ser 40:41-51

Lawrence JM, Agatsuma Y (2001) The ecology of Tripneustes. In: Lawrence JM (ed) Edible sea urchins: biology and ecology. Elsevier Science, New York, p 395-413

Lessios HA (1988) Mass mortality of Diadema antillarum in the Caribbean: What have we learned? Annu Rev Ecol Syst 19:371-393

Lewis SM, Wainwright PC (1985) Herbivore abundance and grazing intensity on a Caribbean coral reef. J Exp Mar Biol Ecol 87:215-228

McClanahan TR, Muthiga NA (2001) The ecology of Echinometra. In: Lawrence JM (ed) Edible sea urchins: biology and ecology. Elsevier Science, New York, p 225-243

McClanahan TR, Polunin NVC, Done TJ (2002a) Ecological states and the resilience of coral reefs. Conserv Ecol 6:(2):48. Available at www.consecol.org/vol6/iss2/art18/

McClanahan TR, Polunin NVC, Done TJ (2002b) Resilience of coral reefs. In: Gunderson L, Jansson BO, Hollings CS, Folke C (eds) Resilience and the behavior of large-scale ecosystems. Island Press, Washington, DC, p 111-163

McCook LJ, Jompa J, Diaz-Pulido G (2001) Competition between corals and algae on coral reefs: a review of evidence and mechanisms. Coral Reefs 19:400-417

McManus JW, Menez LAB, Kesner-Reyes KN, Vergara SG, Ablan MC (2000) Coral reef fishing and coral-algal phase shifts: implications for global reef status. ICES J Mar Sci 57:572-578

Miller MW (1998) Coral/Seaweed competition and the control of reef community structure within and between latitudes. Oceanogr Mar Biol Annu Rev 36:65-96

Morrison D (1988) Comparing fish and urchin grazing in shallow and deeper coral reef algal communities. Ecology 69: $1367-1382$

O'Brien RG (1979) A general ANOVA method for robust tests of additive models for variances. J Am Stat Assoc 74:877-880

Ogden JC (1987) Comparison of the tropical western Atlantic (Caribbean) and the Indo-Pacific: herbivore-plant interactions. UNESCO Rep Mar Sci 46:167-169

Ogden JC, Lobel PS (1978) The role of herbivorous fishes and urchins in coral reef communities. Environ Biol Fish 3:49-63

Potts CD (1977) Suppression of coral populations by filamentous algae within damselfish territories. J Exp Mar Biol Ecol 28:207-216

Risk MJ, Sammarco PW (1982) Bioerosion of corals and the influence of damselfish territoriality: a preliminary study. Oecologia 52:376-380

Robertson DR, (1991) Increase in surgeonfish populations after mass mortality of the sea urchin Diadema antillarum in Panama indicate food limitation. Mar Biol 111:437-444

Russ GR (1987) Is the rate of removal of algae by grazers reduced inside territories of tropical damselfishes. J Exp Mar Biol Ecol 110:1-17

Russ GR (2003) Grazer biomass correlates more strongly with production than with biomass of algal turfs on a coral reef. Coral Reefs 22:63-67

Sammarco PW (1987) A comparison of some ecological processes on coral reefs of the Caribbean and the Great Barrier Reef. UNESCO Rep Mar Sci 46:127-166 
Sammarco PW, Risk MJ, Rose C (1987) Effects of grazing damselfish territoriality on internal bioerosion of dead coral: indirect effects. J Exp Mar Biol Ecol 112: 185-199

Stromberg H, Kvamemo C (2005) Effects of territorial damselfish on cryptic bioeroding organisms in dead Acropora formosa. J Exp Mar Biol Ecol 327:91-102

Watts SA, McClintock JB, Lawrence JM (2001) The ecology of

Editorial responsibility: Otto Kinne (Editor-in-Chief), Oldendorf/Luhe, Germany
Lytechinus variegatus. In: Lawrence JM (ed) Edible sea urchins: biology and ecology. Elsevier Science, New York, p 375-394

Williams AH (1981) An analysis of competitive interactions in a back-reef environment. Ecology 62:1107-1120

Williams ID, Polunin NVC (2001) Large-scale associations between macroalgal cover and grazer biomass on middepth reefs in the Caribbean. Coral Reefs 19:358-366

Submitted: February 7, 2006; Accepted: June 6, 2006

Proofs received from author(s): February 7, 2007 